\title{
Introduction to the special issue on advances in the understanding of reading comprehension deficits
}

\author{
Laura A. Barquero ${ }^{1} \cdot$ Laurie E. Cutting ${ }^{1}$ \\ Published online: 20 June 2021 \\ (C) The International Dyslexia Association 2021
}

Decades of research have established the importance of recognizing and decoding words proficiently to be a good reader; indeed, difficulty with recognizing and decoding words is a hallmark characteristic of dyslexia. To this end, the cognitive characteristics of and intervention approaches for those with dyslexia have taken center stage in reading research. Nevertheless, while much remains to be understood about dyslexia, the endpoint of readingreading comprehension-remains understudied in comparison to word-level processes, particularly in those who struggle specifically with reading comprehension. This is important as studies have shown that while word-level processes are necessary, they are not sufficient for reading comprehension (e.g., Catts et al., 2006; Oakhill et al., 2003). On the more extreme end, this is represented by the fact that approximately $10 \%$ of poor comprehenders do not have deficits at the word level (Catts et al., 2003; Nation \& Snowling, 1998; Stothard \& Hulme, 1995). This class of poor readers is referred to as those with Specific Reading Comprehension Deficits (S-RCD).

$\mathrm{S}-\mathrm{RCD}$ is a particularly intriguing poor reader profile as it is illustrative of the need to understand comprehension processes as distinct from word-level processes. S-RCD has emerged not only as a behavioral profile but also as a corresponding neurobiological profile, resembling typical readers in areas of orthographic and phonological processing, but with anomalous connectivity between language and declarative memory areas of the brain (Cutting et al., 2013). While S-RCD itself is an important reader profile to study, gleaning an understanding of this reader profile also provides insights about reading comprehension processes more generally. Specifically, by identifying how reading comprehension can go awry, S-RCD highlights the necessary components and processes that transform words on a page to meaningful thoughts and interconnected schemata. Given that more than $60 \%$ of children cannot read proficiently (NAEP, 2019) and ameliorating reading comprehension

\section{Laurie E. Cutting}

Laura A. Barquero

laura.barquero@Vanderbilt.Edu

1 Vanderbilt University, PMB 328, 230 Appleton Place, Nashville, TN 37203, USA 
deficits has been found to be fairly intractable (Scammacca et al., 2013; Wanzek et al., 2013), better understanding the mechanisms of reading comprehension is important, both specifically related to S-RCD and more generally. To this end, this special issue tackles better understanding the mechanisms of reading comprehension and S-RCD from multiple avenues. This set of innovative studies addresses questions surrounding (1) reading comprehension assessment; (2) how S-RCD is distinct from other disorders; (3) profiles of S-RCD in English language learners and their response to intervention; and (4) the intriguing flipside of how some readers can be successful comprehenders despite relatively poor decoding skill. Together, this group of studies brings to light current issues and needed areas of further study in reading comprehension research and practice.

At the outset, understanding reading comprehension starts with the most basic element: understanding how to assess it. Different assessments measure different aspects of reading comprehension (Cutting \& Scarborough, 2006) and honing assessment to identify specific component strengths and weaknesses is necessary. Thus, to understand reading comprehension, we must explore issues of assessment, such as whether multiple-choice versus recall or narrative versus expository text (genre) engages different cognitive processes or differentially impact different various reader profiles. To this end, Kim \& Petscher's (2020) study, using explanatory item response models with a large sample of second graders, examines reader, text, and question type factors that impact listening comprehension outcomes. They found that the largest amount of variance in listening comprehension could be attributed to between-item differences, with additional variance attributed to between-passages differences, and a small amount of variance due to between-child differences. Not surprisingly, their findings reveal that narrative texts are easier to comprehend than expository texts, which mirrors other reading comprehension studies (Best et al., 2008; Wu et al., 2020). However, counterintuitively, they show that poor readers performed slightly better on inferential as compared to literal questions, thus underscoring the need to develop a better understanding of how item features in comprehension assessments interact with readers' profiles. The second paper in this special issue that tackles assessment is by Collins et al. (2021), who show that type of comprehension question (open ended, multiple choice, recall) accounted for more of the variance in reading comprehension outcomes than did text genre (narrative, expository) or language knowledge group (emerging, basic, proficient; as measured by a composite of listening comprehension, vocabulary, and general academic knowledge). Furthermore, their results suggest that for those with emerging language knowledge, reading comprehension is likely to be dependably measured by any of the three question types if sufficient numbers of questions are included in the assessment; however, for those with language knowledge at the basic or proficient level, a single question type is less dependable in capturing reading comprehension. Together, these findings suggest that understanding more about the processes of reading comprehension, including a more nuanced approach in how to assess it, needs to be an area of continued research. Improvements in reading comprehension assessment will also ultimately lead to improved identification and understanding of S-RCD.

The second set of papers by Wagner et al. (2021) and Earle and Del Tufo (2021) tackles elucidating the boundaries and underlying components of S-RCD through focusing on how SRCD may be unique from other types of reading difficulties and other disorders. Importantly, Wagner et al. show that the Simple View of Reading, while accounting for substantial variance in reading comprehension, leaves a large amount of variance unaccounted for, indicating that other factors need to be considered. These findings converge nicely with a prior paper from this research group which showed that for those with S-RCD, oral language could not fully 
explain the magnitude of reading comprehension deficits (Spencer \& Wagner, 2018), and therefore highlight the need for understanding additional processes in reading comprehension. Earle and Del Tufo (2021) delve further into the specificity of S-RCD, showing that S-RCD is distinct from those with developmental language disorders (DLD), thus also providing evidence from a different direction that S-RCD cannot be wholly accounted for by language processes, and that other explanatory variables need to be considered. However, as Earle and Del Tufo (2021) illustrate, S-RCD can co-occur with DLD, stressing the need to also recognize that the interplay of S-RCD with other diagnoses may convolute identification and treatment. Their findings additionally suggest that investigation into how S-RCD interacts with other potential aspects of individual profiles is warranted.

The third set of papers explores the influence of readers' English language learner (ELL) status (Li et al., 2021; Martinez-Lincoln et al., 2021). ELL status in particular, versus other categories of students, is linked to reading comprehension because ELLs often show an SRCD-like profile (Farnia \& Geva, 2013; Lesaux et al., 2006), with stronger word-level processes than their reading comprehension proficiency would suggest. Therefore, this population is of interest both practically - given that over $9 \%$ of the US population of students are estimated to be ELLs, with some school districts substantially higher in the USA (IES, 2021) and Canada (Statistics Canada, 2016) — and theoretically, as they too offer more insights into reading comprehension somewhat disassociated from word-level processes. Li et al.'s (2021) findings illustrate this phenomenon, as they show that ELL poor readers showed weaknesses in vocabulary breadth, listening comprehension, and morphological awareness, but were not necessarily distinctive from other reader groups in lower word-level skills. Interestingly, findings revealed that skills such as inference and comprehension monitoring were also not distinctly weak in the ELL group, suggesting that ELL may impact reading comprehension at the linguistic, but not metacognitive, level. Given that Wagner et al.'s and Earle and Del Tufo's findings point to S-RCD being characterized, at least in part, by processes not captured in the linguistic realm, Li et al.'s (2021) results indicate that the origins of the poor reading comprehension may be quite distinct between S-RCD and ELL groups. Such findings could, for example, manifest in terms of different approaches to intervention based on ELL status. To this end, Martinez-Lincoln et al. (2021) offer some supportive findings to this effect, such that responsiveness to different approaches to reading comprehension intervention for poor readers (business-as-usual, teacher-led, versus computer-led) varied by ELL status. Specifically, the computer-led intervention was less beneficial than business-as-usual instruction for ELLs. These findings indicate that perhaps the interactive component of reading instruction is more critical for ELLs, which will need to be unpacked further in future studies. For example, it may be that pragmatics and non-verbal cues are needed in order to engage effective learning strategies for ELLs. Regardless, the more immediate impact of Martinez-Lincoln et al.'s (2021) study may be its implications for allocation school resources, as the current findings suggest that reading comprehension interventions for ELLs may need to rely less on computerled interventions.

The final paper in this collection provides understanding of reading comprehension processes through a sort of juxtaposition with S-RCD. Whereas S-RCD is characterized by poor reading comprehension despite adequate word-level skills, Farris et al. (2021) explore reading comprehension that exceeds that which is predicted by decoding skill. They find that for college students with discrepant levels of reading comprehension and decoding, vocabulary and morphological awareness appear to be protective factors, thus enabling adequate comprehension of text despite relatively weak decoding skills. Previous studies have shown that 
morphological awareness is generally weak in poor comprehenders (e.g., Tong et al., 2014) and Li et al. (2021) found that morphological awareness is lower in ELL poor comprehenders than in English as a first language (EL1) poor comprehenders; conversely, the findings of Farris et al. indicate that morphological awareness may play a role in mitigating word-level deficits for those readers who have effectively bypassed developing strong decoding skills and still attained relatively strong reading comprehension. Farris and Odegard's findings indicate that further understanding what allows for unexpectedly proficient comprehension may provide both theoretically and practically informative insights about reading comprehension.

In summary, each of the themes of the special issue offers insights into the mechanisms of reading comprehension that have both theoretical and practical implications. While much remains to be understood about reading comprehension, each of these studies provides some foundational insights upon which to build future investigations. First, there is a significant need for understanding how text features and reader profiles interact and impact reading comprehension outcomes, including different ways to measure reading comprehension. Second, there is a crucial need to begin to pinpoint the other factors in S-RCD. S-RCD and reading comprehension studies in general have largely relied on the Simple View of Reading (Gough \& Tunmer, 1986); while this is a robust model, identification of the other factors that impact SRCD (and reading comprehension more generally) is needed. While our studies (Cutting et al., 2009; Locascio et al., 2010; Sesma et al., 2009; Spencer et al., 2020) and others' studies (Carretti et al., 2009; Cirino et al., 2019) have pointed to executive function as one potential additional factor in explaining S-RCD, a great deal remains to be understood about the cognitive profiles of S-RCD, including the impact of ELL status on S-RCD/reading comprehension and best approaches to intervention. One fruitful avenue that crosses all the themes within this special issue may be exploring online RC processes, or trying to capture the cognitive processes occurring while readers navigate through a text, which may provide more granularity in teasing apart the issues raised. An approach that may bolster our insights as to how online processes impact reading comprehension, and in particular those with S-RCD, could be leveraging neurobiological methods. For example, functional MRI (fMRI) and/or EEG studies could offer insights about how text features may interact with reader profiles to predict reading comprehension outcomes. fMRI is able to provide information about where in the brain different processes are occurring, and therefore could be a useful tool for capturing online discourse processes in terms of, for example, which areas in the brain are active for processing ideas central to the text's meaning, versus those that are peripheral (cf. Swett et al., 2013), or how brain networks reconfigure while building a situation model (Simony et al., 2016). However, while fMRI can provide sequential information (e.g., how a functional brain network is reconfigured from the beginning of a story versus the middle versus the end (cf. Simony et al., 2016), or which areas of the brain are active for phrases that are linked to more versus less cohesive aspects of text or text types (narrative versus expository texts)), it is limited in terms of providing temporal processing information at the level of milliseconds. EEG, on the other hand, allows for online processing to be explored across the time course of processing a text in a way that differs from and complements fMRI which can be useful, for example, in determining with millisecond precision how good versus poor comprehenders may process related versus unrelated semantic information (cf. Landi \& Perfetti, 2007), but is limited in localizing where in the brain processes are happening.

Because fMRI and EEG can provide a window into what is happening as a reader processes text, such approaches may be particularly insightful for informing construction of texts, including those used for reading comprehension assessment. For example, certain text types 
(e.g., narrative versus expository) or features may be more or less demanding of different brain networks, which could have implications for different reader profiles. Additionally, exploring the neurobiology that underlies difficulty with text comprehension downstream could be used to inform development of intervention approaches, and tease apart the way reader profiles (S$\mathrm{RCD}$, as well as ELLs) process different components of text. For example, studies of individual differences that include biomarkers at baseline to predict growth and/or treatment response could be fruitful for predicting long-term retention of content and responsiveness to intervention in a manner that behavioral studies may not be able to fully capture. Of note, the limited neurobiological studies thus far on S-RCD (or studies examining the incongruence of comprehension from word-level processes) have provided insights that are largely consistent with behavioral findings, including the underlying premise that S-RCD has a profile that is distinct from word-level reading difficulty, resembling typical readers in areas of orthographic and phonological processing (Cutting et al., 2013; Landi \& Perfetti, 2007), and that poorer reading comprehension correlates with anomalous engagement and/or coordination between language areas and executive function areas during discourse processing in adolescent readers with typical decoding skills (Aboud et al., 2016; Ryherd et al., 2018). Altogether, these studies indicate that neurobiological approaches may allow us to further home in on the mechanisms associated with S-RCD, as well as more broadly provide insights into reading comprehension, particularly online discourse processes. Additional considerations for gleaning a greater understanding of S-RCD and reading comprehension could include other ways of capturing online processes, such as indices of mind wandering.

In summary, the process of transforming printed words to cohesive meaning is incredibly complex, and engaging in this line of research is no small feat. As the papers in this issue demonstrate, much has been learned about reading comprehension, yet new questions arise as knowledge is gained. It is our hope that these papers will not only inform on current trends and knowledge but also inspire further research in reading comprehension and S-RCD.

\section{References}

\section{*Denotes Special Issue papers}

Aboud, K. S., Bailey, S. K., Petrill, S. A., \& Cutting, L. E. (2016). Comprehending text versus recognizing words in young readers with varying reading ability: Distinct patterns of functional connectivity from common processing hubs. Developmental Science, 19(4), 632-656. https://doi.org/10.1111/desc.12422.

Best, R. M., Floyd, R. G., \& McNamara, D. S. (2008). Differential competencies contributing to children's comprehension of narrative and expository texts. Reading Psychology, 29(2), 137-164. https://doi.org/10. 1080/02702710801963951.

Carretti, B., Borella, E., Cornoldi, C., \& De Beni, R. (2009). Role of working memory in explaining the performance of individuals with specific reading comprehension difficulties: A meta-analysis. Learning and Individual Differences, 19(2), 246-251. https://doi.org/10.1016/j.lindif.2008.10.002.

Catts, H. W., Hogan, T. P., \& Fey, M. E. (2003). Subgrouping poor readers on the basis of individual differences in reading-related abilities. Journal of Learning Disabilities, 36(2), 151-164. https://doi.org/10.1177/ 002221940303600208.

Catts, H. W., Adlof, S. M., \& Weismer, S. E. (2006). Language deficits in poor comprehenders: A case for the simple view of reading. Journal of Speech, Language, and Hearing Research, 49(2), 278-293. https://doi. org/10.1044/1092-4388(2006/023). 
Cirino, P. T., Miciak, J., Ahmed, Y., Barnes, M. A., Taylor, W. P., \& Gerst, E. H. (2019). Executive function: Association with multiple reading skills. Reading and Writing, 32(7), 1819-1846. https://doi.org/10.1007/ s11145-018-9923-9.

*Collins, A. A., Lindström, E. R., \& Sandbank, M. (2021). The influence of language knowledge and test components on reading comprehension scores. Annals of Dyslexia. https://doi.org/10.1007/s11881-02000212-y.

Cutting, L. E., \& Scarborough, H. S. (2006). Prediction of reading comprehension: Relative contributions of word recognition, language proficiency, and other cognitive skills can depend on how comprehension is measured. Scientific Studies of Reading, 10(3), 277-299. https://doi.org/10.1207/s1532799xssr1003_5.

Cutting, L. E., Materek, A., Cole, C. A. S., Levine, T. M., \& Mahone, E. M. (2009). Effects of fluency, oral language, and executive function on reading comprehension performance. Annals of Dyslexia, 59(1), 34-54. https://doi.org/10.1007/s11881-009-0022-0.

Cutting, L. E., Clements-Stephens, A., Pugh, K. R., Burns, S., Cao, A., Pekar, J. J., Davis, N., \& Rimrodt, S. L. (2013). Not all reading disabilities are dyslexia: Distinct neurobiology of specific comprehension deficits. Brain Connectivity, 3(2), 199-211. https://doi.org/10.1089/brain.2012.0116.

*Earle, F. S., \& Del Tufo, S. N. (2021). Literacy-supporting skills in college students with specific reading comprehension deficit and developmental language disorder. Annals of Dyslexia. https://doi.org/10.1007/ s11881-020-00211-z.

Farnia, F., \& Geva, E. (2013). Growth and predictors of change in English language learners' reading comprehension. Journal of Research in Reading, 36(4), 389-421. https://doi.org/10.1111/jrir.12003.

*Farris, E. A., Cristan II T., Bernstein SE., \& Odegard, T. N. (2021). Morphological awareness and vocabulary predict reading resilience in adults. Annals of Dyslexia.

Gough, P. B., \& Tunmer, W. E. (1986). Decoding, reading, and reading disability. Remedial and Special Education, 7(1), 6-10.

IES. (2021). English language learners in public schools. In Elementary and Secondary Enrollment. Institute of Education Sciences, National Center for Education Statistics (United States). Retrieved from https://nces.ed. gov/programs/coe/indicator/cgf\#:

*Kim, Y. S. G., \& Petscher, Y. (2020). Influences of individual, text, and assessment factors on text/discourse comprehension in oral language (listening comprehension). Annals of Dyslexia. https://doi.org/10.1007/ s11881-020-00208-8.

Landi, N., \& Perfetti, C. A. (2007). An electrophysiological investigation of semantic and phonological processing in skilled and less-skilled comprehenders. Brain and Language, 102(1), 30-45. https://doi.org/ 10.1016/j.bandl.2006.11.001.

Lesaux, N. K., Lipka, O., \& Siegel, L. S. (2006). Investigating cognitive and linguistic abilities that influence the reading comprehension skills of children from diverse linguistic backgrounds. Reading and Writing, 19(1), 99-131. https://doi.org/10.1007/s11145-005-4713-6.

*Li, M., Geva, E., D’Angelo, N., Koh, P. W., Chen, X., \& Gottardo, A. (2021). Exploring sources of poor reading comprehension in English language learners. Annals of Dyslexia. https://doi.org/10.1007/s11881021-00214-4.

Locascio, G., Mahone, E. M., Eason, S. H., \& Cutting, L. E. (2010). Executive dysfunction among children with reading comprehension deficits. Journal of Learning Disabilities, 43(5), 441-454. https://doi.org/10.1177/ 0022219409355476.

*Martinez-Lincoln, A., Barnes, M. A., \& Clemens, N. H. (2021). Differential effectiveness of an inferential reading comprehension intervention for struggling middle school readers in relation to mind-wandering, anxiety, mindset, and English learner status. Annals of Dyslexia. https://doi.org/10.1007/s11881-020-002097.

NAEP. (2019). National assessment of educational progress (NAEP). U.S. Department of Education, Institute of Education Sciences, National Center for Education Statistics. Retrieved from https://nces.ed.gov/ nationsreportcard/reading/

Nation, K., \& Snowling, M. J. (1998). Semantic processing and the development of word-recognition skills: Evidence from children with reading comprehension difficulties. Journal of Memory and Language, 39(1), 85-101 Retrieved from http://linkinghub.elsevier.com/retrieve/pii/S0749596X98925645.

Oakhill, J. V., Cain, K., \& Bryant, P. E. (2003). The dissociation of word reading and text comprehension: Evidence from component skills. Language \& Cognitive Processes, 18(4), 443-468. https://doi.org/10.1080/ 01690960344000008 .

Ryherd, K., Jasinska, K., Van Dyke, J. A., Hung, Y.-H., Baron, E., Mencl, W. E., et al. (2018). Cortical regions supporting reading comprehension skill for single words and discourse. Brain and Language, 186, 32-43. https://doi.org/10.1016/j.bandl.2018.08.001. 
Scammacca, N. K., Roberts, G., Vaughn, S., \& Stuebing, K. K. (2013). A meta-analysis of interventions for struggling readers in grades 4-12: 1980-2011. Journal of Learning Disabilities, 0022219413504995, 369390. https://doi.org/10.1177/0022219413504995.

Sesma, H. W., Mahone, E. M., Levine, T., Eason, S. H., \& Cutting, L. E. (2009). The contribution of executive skills to reading comprehension. Child Neuropsychology : A Journal on Normal and Abnormal Development in Childhood and Adolescence, 15(3), 232-246. https://doi.org/10.1080/09297040802220029.

Simony, E., Honey, C. J., Chen, J., Lositsky, O., Yeshurun, Y., Wiesel, A., \& Hasson, U. (2016). Dynamic reconfiguration of the default mode network during narrative comprehension. Nature Communications, 7(May 2015), 1-13. https://doi.org/10.1038/ncomms12141.

Spencer, M., \& Wagner, R. K. (2018). The comprehension problems of children with poor reading comprehension despite adequate decoding : A meta-analysis. Review of Educational Research, 88(3), 366-400. https:// doi.org/10.3102/0034654317749187.

Spencer, M., Richmond, M. C., \& Cutting, L. E. (2020). Considering the role of executive function in reading comprehension: A structural equation modeling approach. Scientific Studies of Reading, 24(3), 179-199. https://doi.org/10.1080/10888438.2019.1643868.

Statistics Canada. (2016). Retrieved from https://www12.statcan.gc.ca/census-recensement/2016/rt-td/lang-eng. cfm

Stothard, S. E., \& Hulme, C. (1995). A comparison of phonological skills in children with reading comprehension difficulties and children with decoding difficulties. Journal of Child Psychology and Psychiatry, 36(3), 399-408. https://doi.org/10.1111/j.1469-7610.1995.tb01298.x.

Swett, K., Miller, A. C., Burns, S., Hoeft, F., Davis, N., \& Petrill, S. A., \& Cutting, L. E. (2013). Comprehending expository texts: The dynamic neurobiological correlates of building a coherent text representation. Frontiers in Human Neuroscience, 7(December), 853. https://doi.org/10.3389/fnhum.2013.00853.

Tong, X., Deacon, S. H., \& Cain, K. (2014). Morphological and syntactic awareness in poor comprehenders: Another piece of the puzzle. Journal of Learning Disabilities, 47(1), 22-33. https://doi.org/10.1177/ 0022219413509971.

*Wagner, R., Beal, B., Zirps, F. A., \& Spencer, M. (2021). A model-based meta-analytic examination of specific reading comprehension deficit: How prevalent is it and does the simple view of reading account for it? Annals of Dyslexia.

Wanzek, J., Vaughn, S., Scammacca, N. K., Metz, K., Murray, C. S., Roberts, G., \& Danielson, L. (2013). Extensive reading interventions for students with reading difficulties after grade 3. In Review of Educational Research, 83, 163-195. https://doi.org/10.3102/0034654313477212.

Wu, Y., Barquero, L. A., Pickren, S. E., Taboada, A., \& Cutting, L. E. (2020). The relationship between cognitive skills and reading comprehension of narrative and expository texts: A longitudinal study from Grade 1 to Grade 4. Learning and Individual Differences, 80(February), 101848. https://doi.org/10.1016/j. lindif.2020.101848.

Publisher's note Springer Nature remains neutral with regard to jurisdictional claims in published maps and institutional affiliations. 